disciple of Izaak Walton! There was a goodly eel on the hook, sure enough.

Since then "Winifred" has once again attempted to pull out the line under exactly similar circumstances. Surely this con duct shows powers of observation and of inference of no mean order?

I may add that the collie is now three years old. She saw me fishing many times last summer, and, as I said before, always showed great interest in what was going on. But it was not till six weeks ago that I had any idea how much she was profiting by what she saw.

Perhaps some of your other readers who fish, and are accompanied by intelligent dogs, may have observed similar instances of reasoning power. Seeing to what rerfection dogs can be trained to take part in other branches of sport, perhaps it is not very surprising that here and there one should show a little appreciation of the leading points of the "gentle art" of angling.

The Hollies, Cwm Newydd, Holywell, Morgan J. ROBERTS

North Wales, August 31

\section{Copper and Cholera}

NEED we go to Sweden to test the theory that copper is a preservative against cholera? The year before the i 865 epidemic I travelled by train past Swansea, and my attention was called to the utter want of verdure in the surrounding country, due, I was told, to the copper fumes.

Now, according to the official report, the deaths from cholera in Swansea were 88 in Io,000 in I866, in Neath 79, i I Llanelly, $76-$ all places in the same neighbourhood; thus showing a far greater mortality for the copper-smelting district than any other in England or Wales. The mortality for all England was only 13 in 10,000, and for London 18 . The only two places which in any degree approach Swansea are West Ham with 50 , and Liverpool with 54 ; in both of which it is well known cholera was especially severe. The epidemics of 1849 and 1854 present Swansea in a more favourable light.

Perhaps some of your Swansea readers, by giving the number of deaths-if any-among the actual workers in the metal, can help those who, like myself, are inclined to believe in copper as a prophylactic; in what way I scarcely know, unless it be according to the principles of homoeopathy, as my experience on three occasions-and a lively time I had of it-iead me to believe that copper added to plums to preserve their colour should be eschewed, at any rate in cholera times.

Dulwich, September I

\section{B. G. Jenkins}

\section{The Meteor of August ig}

THE same meteor was undoubtedly seen by Mr. Crispin at Wimbledon, Mr. Pooley at Cheltenham, and myself at Llandudno, and I think I can remove Mr. Crispin's difficulty,

The apparent fall of meteors towards the earth is generally an effect of perspective. An object at a great height moving directly away from the observer appears to move perpendicularly downwards. If moving away obliquely to right or left, it appears to have a more or less horizontal path with a downward inclination.

This meteor was evidently not moving towards the eartb, but was one of those that skim the upper atmosphere, white-hot at their surfaces while the resistance is sufficient, and dark again as soon as they pass into a thinner medium. I suppose it to have first become luminous when directly over Essex, not far from Chelmsford, at a height of about seventy miles, passing northeast over the sea, and vanishing near the Texel. It; appearance along such a path would agree very fairly with the three observations, except that, if Mr. Pooley saw it first quite south-east by compass, it must have been luminous for a second or two before Mr. Crispin or myself observed it, and the starting-point would be nearly over London.

I was wrong at first in referring to the Yorkshire coast. The visible path was clearly south of the Humber.

Crickley Hill, Gloucester, September 2 Albert J. Mott

THE ISCHIAN EARTHQUAKE OF JULY 28, I883 SINCE my last letter to NATURE most of my time has $S$ been occupied in visiting different parts of the island, and although there are still a number of objects to be carefully examined the general features of the catastrophe I hope to have cleared up.

The actual moment of the earthquake is unknown, but seems to have been about 9.25 p.m. ; so, supposing the shock registered at Naples and Vesuvius to be identical with that of Casamicciola, had the observation of time at the latter locality been correct, we could calculate the velocity of transmission, but which it is to be feared is impossible.

As mentioned in NATURE, the shock was preceded by general seismic disturbances throughout Southern Europe. In the island itself we have the most contradictory statements as to premonitory signs and symptoms. One gentleman noticed on two occasions previously his watch, which was suspended by a nail to the wall, swing backwards and forwards. The assertion about the water at Gurgitella being much hotter some days before is of little value without proper thermometric observations, since it is known commonly to vary $20^{\circ} \mathrm{C}$., and may reach more than $40^{\circ}$ from time to time, and I am acquainted with a thermal spring at Bagnoli, near Naples, that varies $23^{\circ}$ $\mathrm{C}$., ranging from $13^{\circ}$ to $36^{\circ} \mathrm{C}$. Perhaps the most remarkable of these kinds of statements was couched in these words:- "The syndic of Serrara Fontana (a town on the south of the island) telegraphed to the Minister of Public Affairs to the effect that in that country a fissure one kilometre long, thirty metres broad, and of unknown depth, from which were issuing dense columns of vapour." On reading this I started immediately for Serrara, and there the syndic placed at my disposal his two informants as guides. After a climb of three hours and a half along the almost impassable sides of Epomeo, we came to its northern slope over Lacco Ameno, with the two landslips I had visited and photographed thirty-six hours after the shock. The fissures were such as take place along the edges of all landslips. No vapour was issuing, and its presence for a short time after the earthquake could be easily explained: the locality is part of the old fumarole area of Monte Cito, where alum was manufactured centuries ago; the rock is much decomposed by the continual escape of acid vapour, and only required the earthquake to shake it down; when the displacement took place a large surface of hot and moist tufa was exposed, and no doubt for some time gave off a quantity of vapour.

It will be seen that not a single point of the size, locality, and characters of the fissure described by the newspaper was correct or free from gross exaggeration. I have visited with care all similar sites of supposed fissures, but after some days of want of shelter, sleep, an abominable starvation diet of bad bread and rotten cheese, combined with continual climbing from daybreak to sunset in an extraordinarily hot Neapolitan summer in the hope of finding some evidence of volcanic action, I did not meet with the slightest success. I was accompanied in these excursions by my friend, Prof. P. Franco of Naples, who shared my disappointment and disgust. Holding as I do the volcanic nature of the earthquake, the appearance of any such phenomena would have been greedily accepted.

If we draw isoseismal lines over the injured districts, we find that they assume the form of elongated ellipsoids whose major axes run nearly east and west.

The fourth isoseismal area, in which houses are only very slightly fissured, not only includes the whole island but must extend into the sea some distance.

One remarkable fact is the manner in which the hou-es of the marinas have suffered much less than others in their immediate neighbourhood, or even farther away from the seismic vertical. This is no doubt due to their foundation reposing on sea sand, which, from the looseness of its particles and therefore inelastic nature, acted as a mattress and absorbed the earth waves. The same fact is observable in all buildings that have their founda- 
tions of the loose alluvial tufas and ash of the plains and valley bottoms, whereas the destruction of houses built on the rock was terrible, thus reversing the well known parable.

Putting aside, however, the speculative side of the question, let us look to facts. From a careful examination of observed azimuths and angles of emergence all point to a plate-shaped focus, whose strike extends in a line from Fontana, just west of Menella, to near the beach at Lacco. The plane of this fissure is probably roughly perpendicular to the surface, but may slightly dip towards the east as the isoseismals are slightly nearer on the eastern side of the seismic vertical, which as a necessity is not represented by a point, but a line on the surface. The rupturing of this plate-like fissure was apparently greatest at a point nearly midway between its extremities.

The remarkable fact that I observed in the earthquake of $\mathrm{I} 88 \mathrm{r}$ that at Fontana the shock was almost vertical like that at Menella is again repeated; for which $I$ then proposed as an explanation the conduction along a tube or column of highly elastic trachyte, filling the old chimney of Epomeo, whilst the surrounding districts were protected by the less elastic mattress of subjacent tufa. On the present occasion Fontana, as before, has all its houses fissured in such a manner as to demonstrate a vertical shock; but besides there is another set of cracks which show a north to south path for a wave at a low angle of emergence. At St. Nicola part of the altar has rocked in the same direction, and between these two localities a rock has been ruptured and projected to the south. Whatever may be the explanation accepted, the fact remains as unique in seismological history.

That Vesuvius did not, or only to a slight extent, sympathise with the seismic movement in the islant of

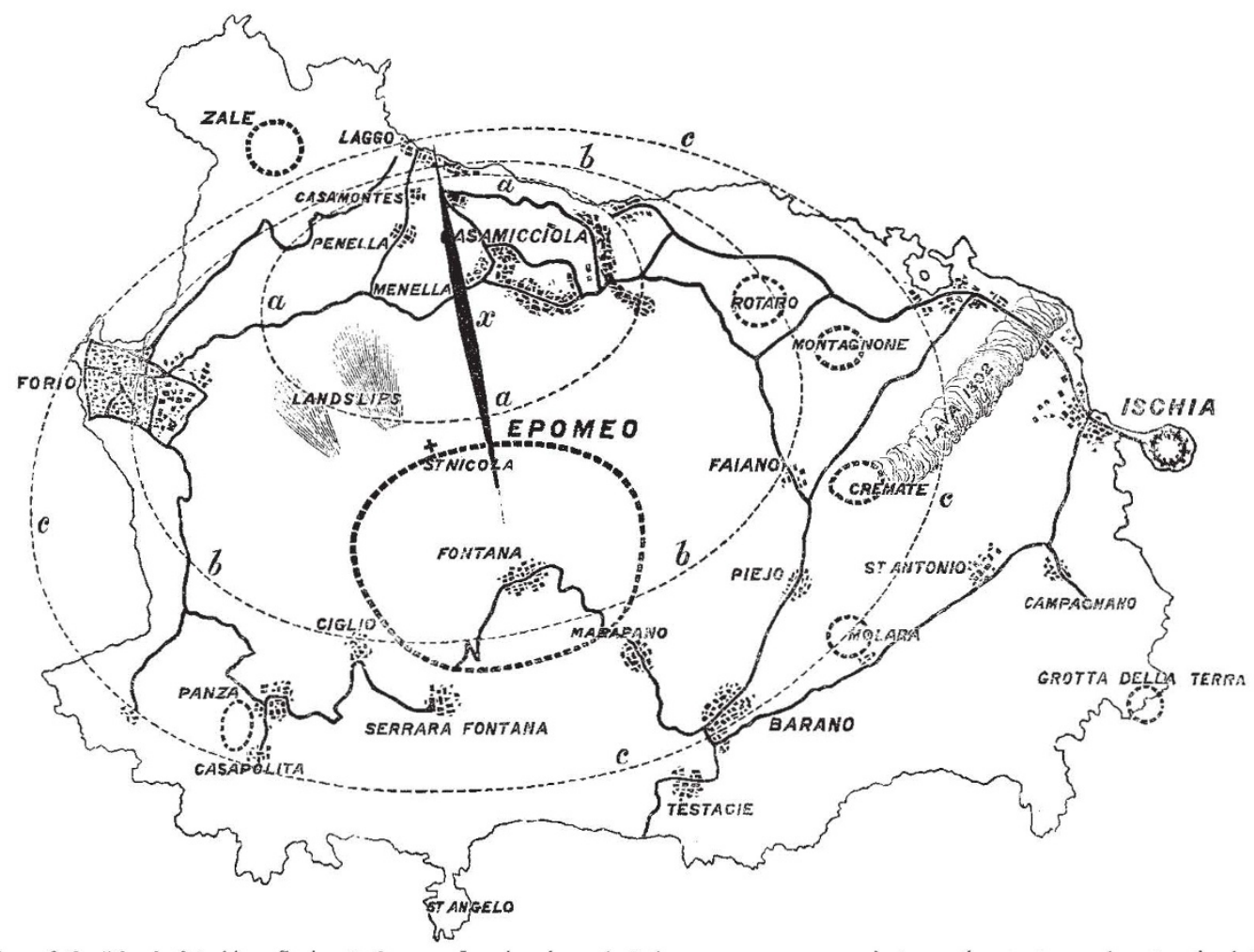

Sketch Map of the Island of Jschia. Scale $x$ to 80,000 . Isoseismals marked thus .................; ancient eruptive centres and craters in do:ted circles. $a$, mesoseismal area $=$ total destruction; $b$, first isoseismal $=$ many houses fallen, rest require rebuilding; $c$, second isoseismal $=$ severely fissure . The third isoseismal does not seem to cut the land; its limits, therefore are unknown. $x$, fissure, or fucal centre.

Ischia is no proof against the volcanic origin of the earthquake. Admitting the hypothesis of a seismic wave traversing a large tract of volcanic matter underlying Southern Europe, such a wave may produce very slight variation at volcanic vents, but may yet be sufficient to determine the extension by rupture of a fissure, where the resistance of the rock, and the tension of the volcanic matter near the point of extension, are nearly equal. In a paper lately read before the Geological Society of London I endeavoured to prove that the explosive violence of lava is due to the assimilation or solution of water taken up from the water-bearing strata it traverses in its passage from the main source towards the surface. Under such conditions we may have very violent phenomena produced, locally, without any sympathy in neighbouring volcanic vents ; which at the same time explains I believe one volcano bursting out in a violent paroxysmal eruption, whilst a near companion is in no way affected. Why therefore should an abortive paroxysm disturb a neighbouring active vent, as in the present example?

In various points that I have examined the coast of the island, there was no apparent change of level, nor did any success attend endeavours to discover any signs of depression of the surface.

It has been stated that the sea receded, but I could not obtain any confirmation of the fact. As the steamer that lay at anchor in the roads felt the shock, it may probably have been due to the disturbance of the water by the earth waves.

As far as my inquiries have gone, the first symptom was a distant sound like that of a carriage, almost immediately accompanied by a tremor, then a terrific explosion shading off into a number of reports. Most people not in the mesoseismal area felt first the "susultatorio" or vertical movement, followed by the undulatory, or, more properly, lateral motion. This, as is well known, is due 
to the arrival first of the emergent wave, followed by the progress outwards and along the surface of others from the seismic vertical. On the contrary, those in the mesoseismal area felt the blow and report apparently simultaneously; the walls fell before any attempt at an escape could be made. It appears therefore that the sound waves travel faster than those of the earth, though the difference in arrival is inappreciable at short distances from the seismic vertical.

Since the principal shock the following minor ones have been felt :-

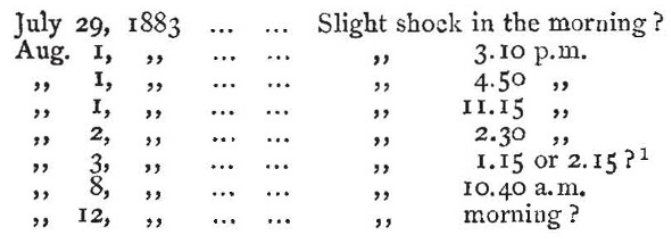

The accessibility of the island, the advanced state of our geological knowledge of it, and the small extension of the earthquake area, make it most suitable and convenient for the study of its terrestrial movements. What is required is a number of seismographs scattered over the island, which should be capable of registering azimuth, angle of emergence or molecular velocity, with the exact time of each movement so as to obtain velocity of transmission. These should be distributed in two circles around the seismic vertical, and should be at least sixteen in number, eight being in each circle, one or more for registering vertical waves to be placed along the seismic vertical. Accurate thermometric measurements of the principal fumaroles and mineral springs to be registered hourly, and if possible some device for measuring quantity of outflow of mineral waters, and pressure of vapour in fumaroles. To these it might be useful to add microseismic observations. The changes in sea level would be of interest if compared with those of Naples.

The principal expense would be providing the instruments, which could be placed in caves cut in the solid tufa, of which there are hundreds in the island that could be obtained for almost nothing, if not entirely free of expense.

By such means we might study the true nature of these shocks, the progress of the focus towards the surface, and verify whether any premonitory signs are to be depended upon preceding an earthquake.

I would impress on all persons charitably inclined that money spent on such an enterprise would be procluctive of far more good than when distributed to be spent in rebuilding the perilous houses of masonry in preparation for another catastrophe. Not six days after the terrible event, masons were at work repairing the most dangerous walls, and many inhabitants have already returned to reside in their fissured and crumbling abodes. Besides, if another shock occurs more violent than the last, a large number of additional localities would suffer, such as Forio and Ischia, besides the villages on the south coast of the island.

H. J. JOHNSTON-LAvis

P.S.-In collecting evidence of ihe Ischian earthquake a very remarkable fact was communicated by Mr. Petersen, the engineer of the Zoological Station at Naples. Whilst dredging on the north side of the unfortunate island, about opposite the cemetery of Casamicciola, a number of pieces of pumice were found floating on the water, some of them as large as a man's head; they had quite a fresh appearance. The conclusion is that there has been a submarine eruption somewhere near the island. Such would explain the sensations felt on board the steamers and the apparent disturbance of the coast line. On the other hand it is strange that the eruption I Which was much stronger and produced slight damage. left no other signs, and that nothing was observable the next morning. No dead fish were noticed. The pumice might be derived from loose deposits containing that material, which form some of the sea cliffs which were shaken down by the earthquake. Whatever be the real cause, we propose to investigate it thoroughly by dredging and diving, as the water rarely exceeds twenty to thirty fathoms at the most.

Naples, August 3I

\section{THE BERNISSART IGUANODON}

THE wonderful discovery of remains of Iguanodons made at Berrissart in 1878 caused quite a sensation amongst naturalists at the time, and the publication of the scientific results of that grand find have been awaited ever since with eager expectation. Nevertheless, as five years have elapsed since the discovery was announced, it is well that the memory should be refreshed by a few brief details as to the circumstances of the find itself before the results as to the nature of the Iguanodons themselves, lately made public, are referred to. Bernissart is in Belgium, situate between Mons and Tournai, close to the French frontier. In the spring of 1878 , in one of the galleries of a coal mine there, were discovered in Wealden clays a large number of bones. Specimens of these bones were forwarded to Professor P. J. van Beneden, who at once recognised them as belonging to Iguanodon.

It is to M. Fagès the director general of the Bernissart Mining Company that the discovery is due. $\mathrm{He}$ interested himself greatly in the matter, and from first to last the mining company has most generously and meritoriously devoted its best resources to the recovery from the depths of the earth in the most perfect condition possible of these most remarkable scientific treasures. It has presented them all to the Royal Museum of Brussels. The actual removal of the specimens from their beds and their transmission to the surface, was performed under the immediate superintendence of $\mathrm{Mr}$. Gustave Arnould, chief engineer, and of M. De Pauw, the latter being the superintendent of workshops at the Brussels Museum, who has since successfully mounted the enormous skeleton shown in the accompanying engraving. So immensely abundant were the remains found to be that Mr. De Pauw assumed for three years the habits of a miner, watching and controlling the removal of every specimen. He invented an ingenious method of hardening the bones in situ which prevented their crumbling when exposed to the air, which at first occurred. The bones exposed on the surfaces of the blocks excavated were covered with a coating of plaster for protection, and the masses thus formed were then raised to the surface, a distance of more than $\mathrm{I}, 000$ feet and removed to cellars under the natural history galleries of the Brussels Museum, to be worked out at leisure. M. Dupont, Director of the Museum, confirmed Professor van Beneden's determination of the bones, and at the same time fixed the exact age of the deposits in which they occurred.

Some surprise has certainly been felt by naturalists that so very little information about the Bernissart skeletons has been published during the time which has elapsed since their discovery, but it must be borne in mind that it took three years even to get the rough material out of the pit, and that every mass of matrix containing bones requires a great deal of most careful labour to be expended on it before the bones in it are fully exposed for study. M. L. Dollo, a distinguished former pupil

× M. L. Dollo, "Première Note sur les Dinosauriens de Bernissart." Bulletin du Musée Royal d'Hist. Nat. de Belgique, T. i. 1882. Deuxième note, Ibid., l.c. Troisième note, Ibid., T. ii. I883. "Note sur la présence chez les oiseaux du Troisième Trochanter des Dinosauriens et sur la function de celui-ci," Ibid., l.c. "Les Iguanodons de Bernissart." Bulletin Scientifique de pédagogique de Bruxelles, April $1,188_{3}$, No. 2, p. 25. 